\title{
AN ASSESSMENT OF PATIENT WAITING AND CONSULTATION TIME IN THE OUTPATIENT DEPARTMENT AT A SELECTED TERTIARY CARE TEACHING HOSPITAL
}

\author{
Radha Thapa1, Sunita Saldanha², Niloufer Bucker ${ }^{3}$, Rishith P4
}

1 Postgraduate Student, Department of Hospital Administration, Yenepoya Medical College.

${ }^{2}$ Associate Professor, Department of Hospital Administration, Yenepoya Medical College.

3 Postgraduate Student, Department of Hospital Administration, Yenepoya Medical College.

${ }_{4}^{4}$ Assistant Hospital Operations Officer, Department of Hospital Administration, Yenepoya Medical College.

\section{ABSTRACT}

\section{BACKGROUND}

Outpatient department has become an essential part of the hospital due to the fact that it is the first step of the treatment system and point of contact between a hospital and community. Waiting time refers to the time a patient waits in the clinic being seen by one of the clinical medical staff.

Objectives-

1. To calculate the patient waiting and consultation time for each specialty.

2. To analyse the cause and effect for the delay.

3. To recommend appropriate suggestions to optimize the waiting time in OPD.

\section{MATERIALS AND METHODS}

A study was carried out using descriptive study design in Yenepoya Medical College Hospital, Mangalore, Karnataka over a period of 3 months and a total of 350 patients were included in this study from various departments such as Medicine, Surgery, Nephrology, Neurology, Oncology, Paediatrics, Ophthalmology, Pulmonary Medicine, Dermatology, Psychiatry, Orthopaedics, Urology, ENT and OBG.

\section{RESULTS}

The average waiting time for all the Outpatient departments was found to be 44.85 minutes. The lowest waiting time was 17.92 minutes and highest waiting time was 126.56 minutes in surgery and nephrology department respectively. Similarly, average consultation time for all the outpatient departments was found to be 17.357 minutes. The lowest consultation time was 6.00 minutes in medicine department and highest consultation time was 76.840 minutes in psychiatry department. After analysing the relationship between consultations and waiting time using Spearman's rank correlation it was found that there was no strong correlation between consultation and waiting time. In ENT department it was found that the re was negative correlation whereas in psychiatry and dermatology departments, there was weak positive correlation.

\section{CONCLUSION}

This study has brought to the surface of certain areas where the hospital needs to pay attention. The main reason for delay was found to be unexpected leave by faculty, disorganized files, delay in mobilization of old file from MRD to OPD etc.

\section{KEYWORDS}

Outpatient Department, Consultation Time, Waiting Time, Quality of Services.

HOW TO CITE THIS ARTICLE: Thapa R, Saldanha S, Bucker N, et al. An assessment of patient waiting and consultation time in the outpatient department at a selected tertiary care teaching hospital. J. Evolution Med. Dent. Sci. 2018;7(08):984-988, DOI: $10.14260 /$ jemds/2018/225

\section{BACKGROUND}

In past years, the concern for service quality reached unprecedented level in various sectors. The success of any healthcare setup depends upon the number of patients coming to Outpatient Department (OPD) each day, the efficiency of the health team, the availability of services and the quality of treatment offered. ${ }^{1}$ Outpatient department has become an essential part of the hospital due to the fact that it is the first step of the treatment system ${ }^{2}$ and point of contact

'Financial or Other Competing Interest': None.

Submission 27-12-2017, Peer Review 06-02-2018,

Acceptance 12-02-2018, Published 19-02-2018.

Corresponding Author:

Radha Thapa,

Yenepoya Medical College,

Department of Hospital Administration,

Deralakatte, Mangalore.

E-mail: kusumradhathapa@gmail.com

DOI: $10.14260 /$ jemds $/ 2018 / 225$

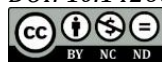

between a hospital and community. OPD is often considered as the window to hospital services and patient's impression of the hospital begins at the OPD. 3

Now a day's OPD services of the majority of hospitals are having queuing and waiting time problem. Waiting time refers to the time a patient waits in the clinic being seen by one of the clinical medical staff ${ }^{4}$. The waiting period is one of the most important indicators of quality of services. Thus, a prolonged waiting time directly reflects on the quality of service being provided. Patients waiting depend on many factors including efficiency, sincerity and punctuality of the health care providers as well as existing facilities of the institution. 5

Long waiting times have been reported in both developed and developing countries. The duration of waiting time varies from country to country, and even within country it varies from center to center. The Institute of Medicine (IOM) recommends that at least $90 \%$ of patients should be seen within $30 \mathrm{~min}$ of their scheduled appointment time. However, 
as several studies have shown that patient spend 2-4 hrs in the outpatient department before seeing the doctor. ${ }^{6}$

Prompt treatment in hospital means to minimize the time for getting a health service with an emphasis on the favourable treatment. Outpatient waiting time has two important aspects. One aspect is that the waiting time of the patients referred by the general practitioner who is created from the time of the entry to the hospital for receiving services, creates great costs and can be modified by techniques of reducing the waiting time. The other one is the waiting time from the time of arrival to the hospital till entering to the examination room. The second part of this time is the waiting time which its major part is related to the hospital and comes to the existence in the hospital. And for reducing the waiting time, hospitals should approach through basic interventions. Regarding the first domain, policy makers should provide the essential procedures and guidelines so that the waiting time for the health care services is reduced to the minimum. ${ }^{7}$

\section{Objectives of the Study}

1. To calculate the patient waiting and consultation time for each specialty.

2. To analyse the cause and effect for the delay.

3. To recommend appropriate suggestions to optimize the waiting time in OPD.

\section{MATERIALS AND METHODS}

A study was carried out using descriptive study design in Yenepoya Medical College Hospital, Mangalore Karnataka over a period of 3 months (May to July 2017). Yenepoya Medical College Hospital is a tertiary care hospital. This hospital is well equipped with all modern technologies and rendering excellent services at an affordable cost.

A simple random sampling technique was used in this study design with a sample size of 350 patients. 25 patients from each of 14 specialties were randomly included in this study. Care was taken to ensure that there was no repetition of the patients. The hospital OPD timing is from 8:30 AM to 3:30 pm, from Monday to Saturday and OPD was closed on Sundays. OPD registration counter opens at 7:30 am and the registration closes at 3:30 pm. Data was collected through direct observation. Time was monitored with the help of stop watch function of mobile phone. The related data was collected from OPD departments such as Medicine, Surgery, Nephrology, Neurology, Oncology, Paediatrics, Ophthalmology, Pulmonary Medicine, Dermatology, Psychiatry, Orthopaedics, Urology, ENT and OBG. The factors causing long patients waiting time were found after interviewing patients, nursing staff, consulting doctor's staff and ancillary staff and fishbone diagram was used to study cause and effect analysis by brainstorming.

\section{Statistical Analysis}

Data was analysed using the statistical package for social sciences (SPSS) version 22.00. Data was presented in figures and tables. It was described by using mean and Kruskal Wallis test. $\mathrm{P}<0.001$ was considered to be highly significant. Spearman's rank correlation was also used to know correlation between patient waiting time and consultation time.

\section{RESULTS}

The average waiting time for all the outpatient departments [Table 1] was found to be 44.85 minutes. The lowest mean waiting time was 17.92 minutes and highest mean waiting time was 126.56 minutes in surgery and nephrology departments respectively [figure 1]. Similarly, average consultation time for all the outpatient departments [Table 2] was found to be 17.357 minutes. The lowest mean consultation time was 6.00 minutes in Medicine department and highest mean consultation time was 76.840 minutes in Psychiatry department [figure 2].

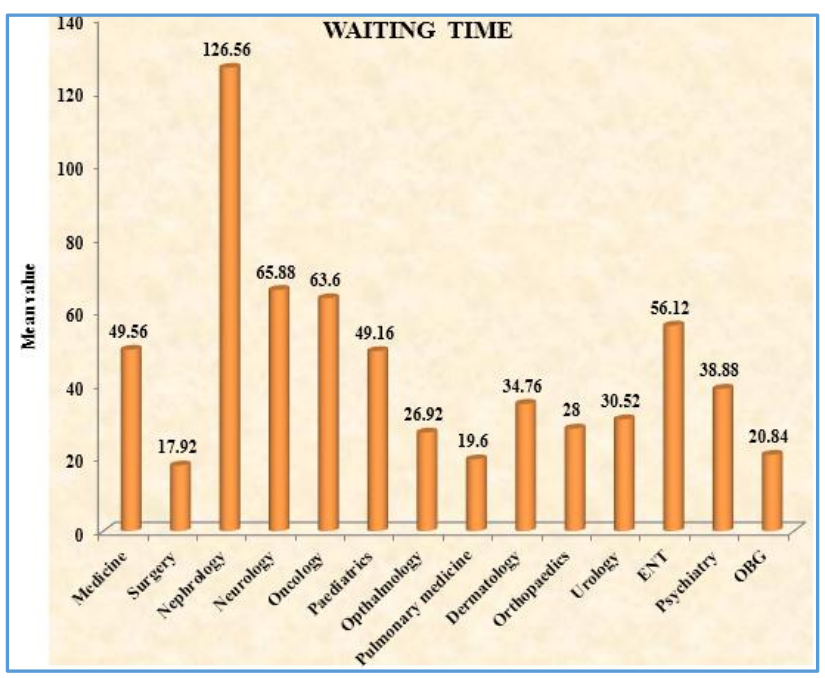

Figure 1. OPD waiting time in various departments

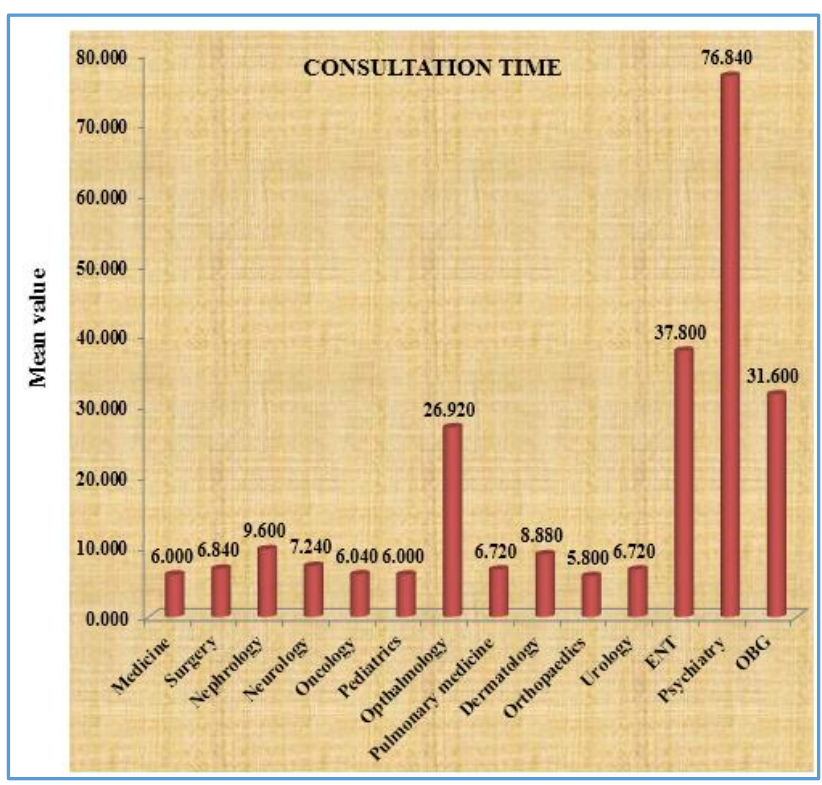

Figure 2. Consultation time in various departments

\begin{tabular}{|c|c|c|c|c|c|}
\hline Department & $\begin{array}{c}\text { Mean } \\
\text { (minutes) }\end{array}$ & $\begin{array}{c}\text { Inter- } \\
\text { Quartile }\end{array}$ & $\begin{array}{c}\text { Minimum } \\
\text { minutes }\end{array}$ & $\begin{array}{c}\text { Maximum } \\
\text { minutes }\end{array}$ & Median \\
\hline Medicine & 49.560 & 15.50 & 15.00 & 65.00 & 54.000 \\
\hline Surgery & 17.920 & 22.50 & 1.00 & 60.00 & 14.000 \\
\hline Nephrology & 126.560 & 220.00 & 0.00 & 300.00 & 81.000 \\
\hline Neurology & 65.880 & 25.00 & 15.00 & 95.00 & 70.000 \\
\hline Oncology & 63.600 & 43.00 & 22.00 & 135.00 & 70.000 \\
\hline Paediatrics & 49.160 & 50.00 & 5.00 & 108.00 & 49.000 \\
\hline Ophthalmology & 26.920 & 22.00 & 1.00 & 55.00 & 25.000 \\
\hline $\begin{array}{c}\text { Pulmonary } \\
\text { Medicine }\end{array}$ & 19.600 & 18.00 & 0.00 & 65.00 & 16.000 \\
\hline
\end{tabular}




\begin{tabular}{|c|c|c|c|c|c|}
\hline Dermatology & 34.760 & 33.50 & 3.00 & 79.00 & 26.000 \\
\hline Orthopaedics & 28.000 & 24.50 & 1.00 & 146.00 & 19.000 \\
\hline Urology & 30.520 & 28.00 & 3.00 & 105.00 & 25.000 \\
\hline ENT & 56.120 & 69.50 & 5.00 & 139.00 & 55.000 \\
\hline Psychiatry & 38.880 & 60.00 & 0.00 & 125.00 & 30.000 \\
\hline OBG & 20.840 & 18.00 & 1.00 & 120.00 & 5.000 \\
\hline Table 1. Patients waiting time in various departments \\
\hline
\end{tabular}

\begin{tabular}{|c|c|c|c|c|c|}
\hline Department & $\begin{array}{c}\text { Mean } \\
\text { minutes }\end{array}$ & $\begin{array}{c}\text { Inter- } \\
\text { Quartile }\end{array}$ & $\begin{array}{c}\text { Minimum } \\
\text { minutes }\end{array}$ & $\begin{array}{c}\text { Maximum } \\
\text { minutes }\end{array}$ & Median \\
\hline Medicine & 6.000 & 3.00 & 2.00 & 22.00 & 5.00 \\
\hline Surgery & 6.840 & 5.50 & 3.00 & 18.00 & 5.00 \\
\hline Nephrology & 9.600 & 9.00 & 4.00 & 22.00 & 7.00 \\
\hline Neurology & 7.240 & 6.50 & 2.00 & 21.00 & 6.00 \\
\hline Oncology & 6.040 & 4.00 & 2.00 & 15.00 & 5.00 \\
\hline Paediatrics & 6.360 & 4.00 & 2.00 & 15.00 & 5.00 \\
\hline Ophthalmology & 26.920 & 22.00 & 1.00 & 55.00 & 25.00 \\
\hline $\begin{array}{c}\text { Pulmonary } \\
\text { Medicine }\end{array}$ & 6.720 & 3.50 & 2.00 & 14.00 & 6.00 \\
\hline Dermatology & 8.880 & 7.00 & 2.00 & 23.00 & 8.00 \\
\hline Orthopaedics & 5.800 & 6.50 & 1.00 & 15.00 & 4.00 \\
\hline Urology & 6.720 & 8.00 & 1.00 & 28.00 & 4.000 \\
\hline ENT & 37.800 & 33.00 & 4.00 & 68.00 & 35.00 \\
\hline Psychiatry & 76.840 & 25.00 & 38.00 & 105.00 & 75.00 \\
\hline OBG & 31.600 & 33.50 & 6.000 & 65.00 & 33.00 \\
\hline Table 2. Patients consultation time in various departments \\
\hline \multicolumn{7}{|l|}{}
\end{tabular}

Comparison of the patient's waiting and consultation time in OPD of all the fourteen departments were estimated by using Kruskal-Wallis test. It was found that mean difference in waiting and consultation time of various departments in OPD is statistically highly significant as $\mathrm{p}<0.001, \mathrm{H}=106.422$ and $\mathrm{p}<0.001, \mathrm{H}=189.253$ respectively. The relationship between patient waiting and consultation time and the effect of long waiting time on consultation time were analysed to know if there is any correlation between patient waiting and consultation time by using "Spearman's rho correlation" [Table no. 3]. And it was found that there was no strong correlation between consultation and waiting time. In ENT department it was found that there was negative correlation( $(\mathrm{r}=-0.563)$ whereas, in Psychiatry $(\mathrm{r}=0.360)$ and Dermatology department $(\mathrm{r}=0.379)$ there was weakly positive correlation.

\begin{tabular}{|c|c|c|}
\hline Department & $\mathbf{r}$ & P value \\
\hline Medicine & 0.018 & 0.934 \\
\hline Surgery & 0.031 & 0.882 \\
\hline Nephrology & -0.298 & 0.148 \\
\hline Neurology & -0.023 & 0.912 \\
\hline Oncology & -0.162 & 0.440 \\
\hline Paediatrics & -0.098 & 0.640 \\
\hline Pulmonary Medicine & 0.101 & 0.632 \\
\hline Dermatology & 0.379 & 0.062 \\
\hline Orthopaedics & -0.169 & 0.418 \\
\hline Urology & 0.037 & 0.859 \\
\hline ENT & -0.563 & 0.003 \\
\hline Psychiatry & 0.360 & 0.077 \\
\hline OBG & -0.157 & 0.452 \\
\hline \multicolumn{3}{|c|}{$\begin{array}{c}\text { Table 3. Spearman's rho Correlation between patients } \\
\text { waiting and consultation time }\end{array}$} \\
\hline
\end{tabular}

\section{Cause and Effect Analysis}

The cause and effect diagram also known as fishbone (Because of its shape) or Ishikawa diagram (Named after Kaoru Ishikawa, its creator) - is used to visualize the relationship between an outcome and its different causes. The C\&E diagram is an analytical tool that provides a visual and systematic way of linking different causes (input) to an effort (Output) and used to identify the root causes of problem. Sometimes, it is difficult to distinguish between cause and effect, but the distinction is important. [Figure 3] shows fishbone diagram demonstrating the causes leading to increased patient waiting time in OPD.

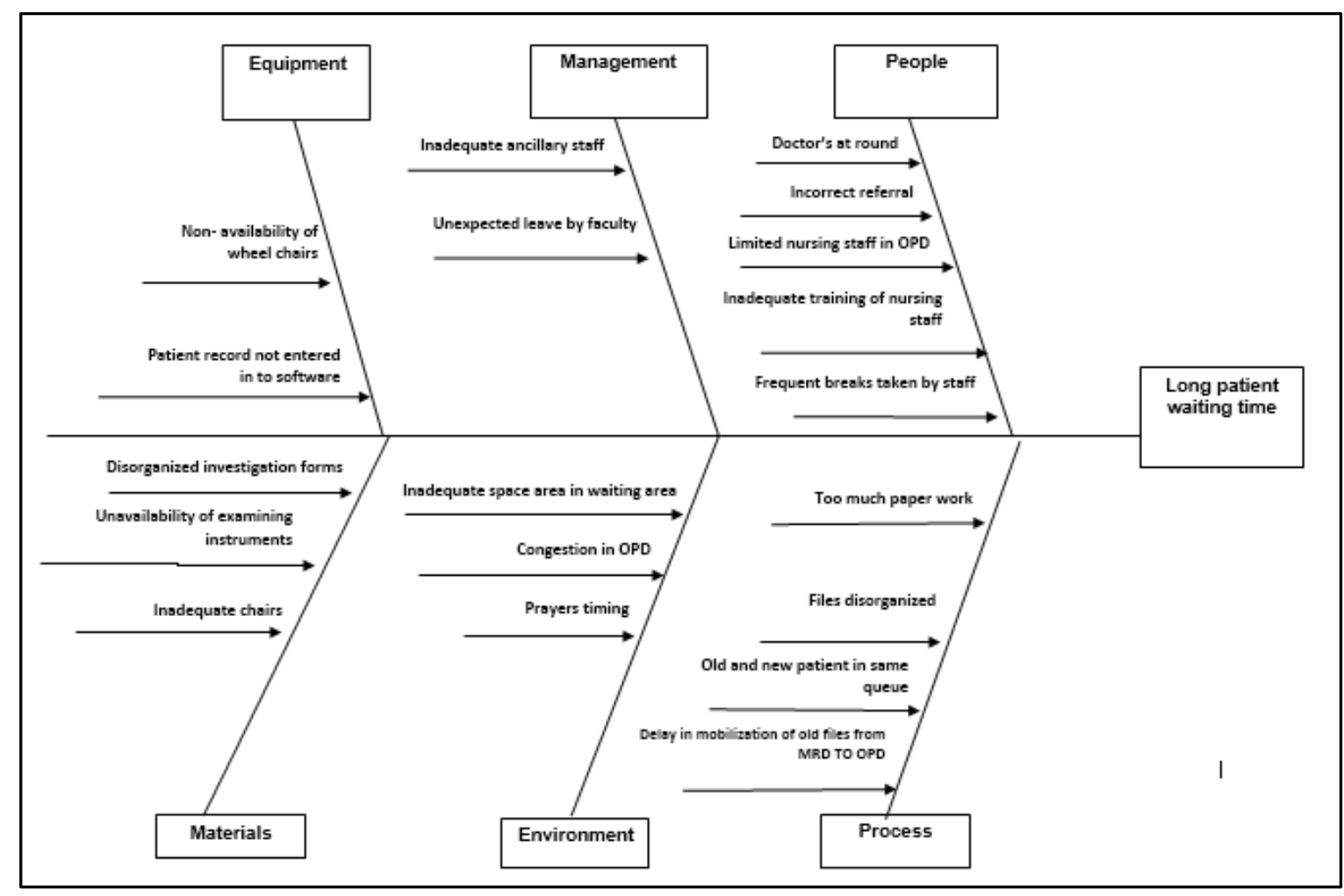

Figure 3. Cause and effect analysis 


\section{Recommendations}

Recommendations were made to reduce waiting time after interviewing patients, relatives, nursing staff and doctors.

\section{They are as follows- \\ People}

- Increase the number of nursing staff with proper training in managing, transferring the patients with language skills and interpersonal relation skills.

- Patient relation executive should be appointed in each OPD who are well trained and able to guide the patient to the concerned department.

\section{Process}

- Token display system to ensure unnecessary overcrowding in front of consultation rooms.

- Doctor's round should be scheduled before OPD timings and break time should be structured to avoid sudden decrease of number of consultants in OPD.

\section{Environment}

- Adequate waiting area with provision of entertainment and health education measures through Television /Newspaper in OPD.

\section{Materials}

- Investigation forms should be kept inside each consultant's room with labeling.

- Complaint and suggestion box should be available in Outpatient Department so that patient could drop their valuable suggestions.

\section{Equipment}

Adequate number of wheelchairs should be available in all OPDs.

\section{Management}

- If a consultant or any staff happens to be on leave, it should be planned, and necessary arrangement should be made in anticipation to avoid inconvenience to the patients well before.

- $\quad$ Critical SWOT (Strengths, Weakness, Opportunities and Threats) analysis of all the OPD areas on regular basis should be undertaken which will go a long way in improving the quality of services in OPD as well as ensuring optimum utilization of services and maximum patient's satisfaction.

- Training of the ancillary staff especially on patient transfer, time management and communication.

\section{DISCUSSION}

Assessment of quality of health care is necessary and compulsory for all health services in such evaluation the participation of patients and their experience as well as their review pays important role. Patients spend substantial amount of time in the waiting area for services to be delivered by physicians and other allied health professionals. The degree to which health consumers are satisfied with the care received is strongly related to the quality of the waiting experience. Failure to incorporate consumer-driven features in to design of wait experience could lead to patient and provider dissatisfaction. ${ }^{8}$ Research shows that in most outpatient department of the teaching hospitals, patients experience longer waiting time to get examined or diverted to private health facilities due to overcrowding thereby reducing healthcare access to the public, and increasing operational cost to hospitals because of the associated inefficiencies.

Those patients who are satisfied from the hospital recommend their friends, relatives, colleagues and others to visit the hospital when they are sick which in turn will have positive impact on revenue of the hospital. If consultation time increases, then some patients may not be able to receive treatment on time. This leads to decrease in bed occupancy. It has been evident that as the patient waiting time increases consultation time decreases invariably because the doctors get pressurized to reduce the congestion and resultant pandemonium in OPD.

In this study waiting time of various departments were as follows; Medicine (Average 49.56 and maximum 65.00 minutes), Surgery (Average 17.92 and maximum 60.00 minutes), Nephrology (Average 126.56 and maximum 300 minutes ), Neurology (Average 65.88 minutes and maximum 95 minutes), Oncology (Average 63.60 minutes and maximum 135 minutes), Paediatrics (Average 49.16 minutes and maximum 108 minutes), Ophthalmology (average 26.92 and maximum 55.00 minutes), Pulmonary Medicine(19.6 minutes and maximum 65.00 minutes), Dermatology (Average 34.76 minutes and maximum 79 minutes), Orthopaedics (Average 28.00 minutes and maximum 146 minutes), Urology (Average 30.52 minutes and maximum 105 minutes), ENT (Average 56.12 minutes and maximum 139 minutes), Psychiatry (Average 38.88 minutes and maximum 125 minutes) and OBG (Average 20.84 minutes and maximum 120 minutes). A similar study was conducted by Adam Addissie; et al. (1997) in the outpatient departments of Jimma Hospital. The main aim of this study was to assess the patient waiting time and service time. A cross- sectional study of 853 patients was done and the time of arrival and departure was recorded using wrist watches. The result of the study was that it took about 9 hours and 13 minutes for a patient to finally leave home, out of which $49.6 \%$ spent waiting for services 9. Aeinparast et al. (2009) also conducted study on estimating outpatient waiting time: a simulation approach. In this study, simulation model outputs showed that the mean patient waiting time for examination by novice resident was about 58 minutes, for experienced resident was about 52 minutes and for attend was about 53 minutes. Review of examination process with simulation model showed that about 42-62 percent of patients' waiting time for examination was before physician arrival at clinic. There were no statistical differences between new and follow-up patients' waiting time and waiting time for primary and complementary examination by residents and attend 10 . A study was conducted by MO Oche et al. (2013) which aimed at assessing the determinants of patients waiting time in general outpatient department of a tertiary healthcare institution in northern Nigeria. It was concluded that sixty-one percent (59/96) of the respondents waited for 90-180 minutes in the clinic, whereas $36.1 \%$ (35/96) of the patients spent less than 5 min with the doctor in the consulting room. The commonest reason for the long waiting time in the General OPD was the large number of patients with few healthcare workers ${ }^{11}$. Whereas in this study conducted at Yenepoya Medical College 
Hospital, it was found that the most common causes of long waiting time in the outpatient department were nonavailability of wheelchairs on time when needed, patient record not entered into computer software, disorganized investigation forms, unavailability of clinical examination instruments when needed, inadequate ancillary staff, unexpected leave by staff, prayer timing and incorrect referral.

\section{CONCLUSION}

Waiting time is one of the most significant problems in every healthcare system. This study has brought to the surface of certain areas where the hospital needs to pay attention. The main reason for the delay was found to be unexpected leave by faculty, disorganized files, delay in mobilization of old file from MRD to OPD, limited nursing staff, prayer timings and doctors at rounds etc. The current study touches very important aspects of Outpatient Department services i.e. patient waiting time and consultation time. This study attempted to assess the patients waiting and consultation time in various departments at a tertiary care hospital with a view to improve them by identifying the gaps and bridging them by addressing causes for delay. In addition, this study also tried to identify correlation between patients waiting and consultation time in different departments and it was found that there was no strong correlation between consultation and waiting time. Subsequently, quality of service can be improved in the Outpatient Department by supportive visionary leadership by healthcare manager, proper planning, education and training, effective management of resources, collaboration and co-operation among the service providers.

\section{REFERENCES}

[1] Bither S, Gandhi S. An audit of patients attending outpatient services of Department of oral and maxillofacial Surgery at Christian Dental College,
Ludhiana, Punjab, India. J Educ \& Ethics in Dent 2011;1(1):28-32.

[2] Lailomthong N, Prichanont S. Patient's waiting time reduction in outpatient department. ICAET 2014: p. 468-73.

[3] Javed D. A time-motion study of OPD services at state level Ayurvedic hospital to reduce the OPD congestion. International Ayurvedic Medical Journal 2015;3(10):1-9.

[4] Rossister CE, Raynolds FA. Automatic monitoring of the time waited in an outpatient clinic. Journal Storage Med Care 1968;1:218-25.

[5] McGibony. Principles of Health Administration. 2 $2^{\text {nd }}$ edn. New York: GP Putanam's Sons 1959.

[6] Sundresh N, Nagmothe RV. A study of determinant of long waiting period in Outpatient Department and recommendation on reducing waiting time in superspeciality hospital. JMSCR 2017;5(12).

[7] Mohebbifar R, Hasanpoor E, Mohseni M, et al. Outpatient waiting time in health services and teaching hospital: a case study in Iran. Global Journal of Health Science 2014;6(1):172-80.

[8] Khatoon KF, Reddy BK, Guvva S. Reducing patient waiting time in dental clinic according to treatment type. International Journal of Community Health and Medical Research 2016;2(4):3-8.

[9] Addissie A, Jira C, Bekele F. Patient waiting and service time in the outpatient department of Jimma Hospital. Ethiopian Journal of Health Sciences 1998;8(1):15-21.

[10] Aeinparast A, Tabibi SJAD, Shahanaghi K, et al. Estimating outpatient waiting time: a simulation approach. Payesh 2009;8(4):327-33.

[11] Oche MO, Adamu H. Determinants of patient waiting time in the general outpatient department of a tertiary health institution in North Western Nigeria. Ann Med Health Sci Res 2013;3(4):588-92. 